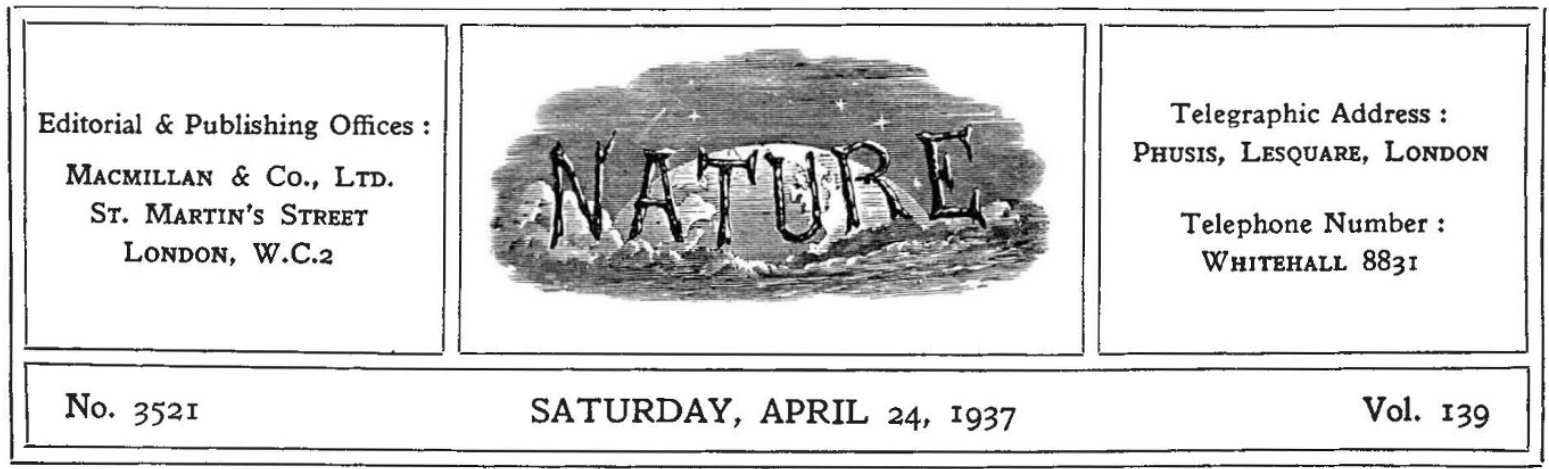

\title{
Social Responsibilities of Science
}

$\mathrm{O}$ $\mathrm{NE}$ of the most significant features of representative scientific gatherings in recent years, even of such widely differing types as the British Association, the World Power Conference, the Society of Chemical Industry, or the Association of Scientific Workers, as in the reports of Carnegie Institution of Washington or the Carnegie Endowment for International Peace, is the concern which has been expressed at the social consequences of the application of scientific discoveries. The necessity for concrete action in this field has been emphasized in recent months in different ways by the attention being given to the problems of the Special Areas, the rearmament programme and the growing malaise in Europe. We are witnessing a race between scientific progress and social instability.

It is accordingly appropriate and welcome that the International Council of Scientific Unions, meeting for the first time in London, should have before it a proposal submitted by the Royal Academy of Sciences at Amsterdam for the appointment of a committee to endeavour to co-ordinate views advanced in recent years regarding the social responsibilities of science and scientific workers (see p. 697).

At present, however, it is difficult for any scientific worker to get a sufficiently clear and ample picture of the problems confronting us and their implications. The proposal, therefore, aims at providing a means of collecting the various opinions which have been brought forward in this sphere and presenting them in a form which may help individual scientific workers and scientific organizations to obtain a better view of their work and of their position in relation to social problems. In support of the proposal a memorandum which has been forwarded to the General Secretary of the International Union bears the signatures of seventy-four scientific workers from different countries, although in inviting support of its proposal the Amsterdam Academy did not address itself to men of science in Germany, in Italy or in the Union of Soviet Socialist Republics, on the ground that in these countries at present scientific workers are bound much more closely to their respective Governments than is the case elsewhere. Nor has support been sought from scientific workers who have emigrated from these countries; in the first instance, an endeavour has merely been made to ascertain the attitude to the proposal of men of science in countries where there is more freedom to express individual opinions.

That such a discrimination should be necessary in the twentieth century is a striking reminder that science has a spiritual message as well as its material aspect, and that it demands a supreme loyalty to truth which must over-ride all other claims if error and delusion are not to result. The search for truth is not fulfilled by giving bare facts, numbers or abstract theories only; there must be also some sense of values and of perspective.

The cherishing of such ideals is a primary function of professional associations whether on a national or an international plane, but to turn to such a programme of research as that set forth in Sir Josiah Stamp's "The Science of Social Adjustment" is to realize the imperative need for scientific organizations to draw together if the beginnings of an attack on these problems is to be contemplated. Equally it is clear that a bridge must be built from the general but indefinite consciousness of social responsibilities to a definite practical campaign in this field. Clear thinking about 
the social implications of scientific work, of the uses that are being and could be made of science, of the abuse of scientific knowledge, and of the fuller use which could be made of it for promoting general social welfare, is the prelude to effective action.

For such thinking, data must be assembled as basis for judgment, and it will still remain to determine the means of making such judgments more effective in the struggle of opinions by which the world is ruled. In the memorandum which accompanies the proposal of the Amsterdam Academy, the possibility is reviewed of interesting existing organizations in this work, and reference is made in particular to the admirable work of co-operation which has already been fostered by the League of Nations in the field of international health and intellectual co-operation. It is suggested that fuller use might be made of the scientific point of view in the work which the League undertakes in adjusting political and social conditions.

The largest general scientific organization, however, is the International Council of Scientific Unions, and it was at first suggested by the Amsterdam Academy that the International Council might regard it as part of its task to consider opinions brought forward from various sides concerning the attitude which should be taken by scientific workers in relation to the dangers at present menacing the future of our civilization. On this basis consideration of the social responsibilities of science could be introduced into various aspects of the Council's work, particularly that carried out on behalf of the League of Nations.

A mere statement of this kind, however, is too wide to lead to the initiation of any concrete piece of work, and the resolution finally submitted to the Council accordingly proposes the appointment of a special committee in the following terms :

"The International Council of Scientific Unions, already at a former occasion having expressed its faith in the possibility and the necessity of peace between the world's peoples, and being convinced that the 'brotherhood of scientists' can be an important factor towards the establishment of a desire for mutual understanding and helpfulness, considers it to be a part of its task to give attention to the opinions brought forward from various sides concerning the attitude which should be taken by scientists in relation to the dangers which at present menace the future of our civilisation.

"The International Council therefore decides to appoint a Committee, which should attempt to arrive at a co-ordination of what has been proposed in respect to the social responsibilities of science and of scientific workers."

It is intended that this work should be carried out in a way which will relate the points of view expressed so that the result may be a guide for those interested in these matters. Moreover, such a committee would no doubt attempt to formulate some general conclusions which might indicate where scientific thought or the personal influence of scientific workers could assist in analysing and attacking social problems, and which might also help individual scientific workers to choose their own point of view in co-operating to safeguard our cultural advance. At the same time, the committee should serve as a centre of contact for organizations and persons interested in this type of cultural work, and assist in creating between these organizations and persons a feeling of mutual sympathy and of solidarity.

It can scarcely be challenged that such a com. mittee could render almost invaluable service, both in the education of public opinion as to the contribution of science in social matters, and in the stimulation of scientific investigation, as well as of effective co-operation between professional organizations, to provide not merely a definite professional code but also a permanent anchorage or shelter from which members of the profession of science would be free to render their special service and exert their full influence undeterred by political or any other type of prejudice. It is indeed only from some such vantage ground that scientific workers can assist humanity to link up science with ethical values, and derive the courage and the authority needed at times to denounce the abuse of scientific effort or results, and to point out positive means of promoting the well-being and co-operation of mankind.

It is unnecessary at this stage to go further into the programme of activity for the committee sketched by the memorandum. The opportunities which confront us in such matters as nutrition, the problems of the Special Areas and the location of industry, the prevention of accidents and industrial disease, are only a few examples of questions to which reference has recently been made in these columns, in respect of which scientific workers might make an important or decisive contribution. Surveys of these fields, of the possibilities of assuring a certain standard of life through a full use of scientific and technical means of production 
and distribution of food and general commodities, and of the alleviation of poverty and misery ; the prostitution of scientific knowledge for ignoble uses and in particular for purposes of war, and the development of a code of ethics and the question of a right attitude to preparations for war; the study of racial relations and feelings are all touched upon in some detail by the memorandum, and indicate the vast field in which fruitful work could be done. No scientific worker who realizes the benefits which science is able to give to society, or who desires to exert his full influence in social affairs, whether as a citizen or in his special capacity as a scientific worker, can be indifferent to the proposal or programme outlined by the Amsterdam Academy.

What matters above all, even in the collection and co-ordination of the existing material, is the spirit in which the work is carried out. Only as that is dominated by the highest ideals and finest loyalty to that spirit of service inherent in science itself can we expect to arouse the devotion and to create the vision which will enable the many difficulties in the way of effective action to be overcome. Even if the committee starts with a comparatively restricted field, that need not hinder it from rekindling the finest ties of professional loyalties and a vision of the possibilities and benefits which the scientific spirit linked with a sense of human values might bring to mankind. Once that is kindled, the human spirit will not long delay to break the shackles with which craven and retrograde political creeds and nationalist systems have sought to restrain its advance into an age of freedom and plenty, where man's mind and spirit, released from the cramping influence of poverty, disease and war, may ashieve a stature and creative fertility hitherto unknown.

\section{Personalities in Natural History}

\section{Green Laurels :}

the Lives and Achievements of the Great Naturalists. By Donald Culross Peattie. Pp. $38+429$ plates. (London, Bombay and Sydney : George G. Harrap and Co., Ltd., 1937). 12s. 6d. net.

$\mathrm{T}$ HE author enjoyed his book, coining happy and striking phrases and suggesting interpretations of great characters. Goethe is "the father of the German romantic movement in poetry and science" and the Nordic interprets himself as "everything upstanding, gifted, pure, great and superior". Darwin is a "kindly English gentleman known by his good works", whose twenty years' record of silence is unsurpassed. Wallace was the greatest of professional collectors, because "he thought as he collected", but he was an "humanitarian before he was a scientist ... a virtue only in a Romantic" ; "disgraceful wrangles ... never between these two". The old ideas were ancestors of theirs; "they built upon the sunken piers of obsolete wisdom". It is to sketch these "piers of nature's unfolding in the mind of man" that pleasures the author, not a history of biology and an orderly sequence of discovered facts. Plato, Aristotle, Theophrastus, Dioscorides, Galen and Pliny held the field until sixteenth-century Gesner published his "Historia Animalium" with Dürer's illustrations. In this man is seen the universality of science, for, from his Swiss home, he corresponded among others with Belon, whose picture of the bones of man and bird founded comparative anatomy, Rondelet (fish-lover), Aldrovandi (traveller), and Turner.

We are rather pleased to escape Vesalius and Harvey and to think of Borelli and Redi as unruly members of the first "Accademia del Cimento", unknown adventurers "on the rim of a volcano". There is sympathy for, and understanding of, Malpighi, Swammerdam and Leeuwenhoek in the first great days of microscopy. Réaumur is a brilliant of purest water, meteorologist, metallurgist, biologist, creator of entomology. In contrast, Buffon, protégé of the Pompadour, recreator of the Jardin des Plantes, prolific writer, courtier, in his jealousy and pride true forerunner of Cuvier, his fame crushed in our minds by his championship of spontaneous generation against the experiments of Spallanzani. Here were gleams of evolution, but the next volume affirms a belief in the scriptural creation "both as to order of time and matter of fact". Linnaeus appeals, a country "sport", great collector and systematizer without whose work further progress had become impossible. He had forerunners, of course, especially Ray, and they, too, had made approach to the idea of sexuality in plants and its analogue in animals.

It was a glorious age, the collecting of Nature from every clime and isle-and in the story there is no elimination of that personality, which never 